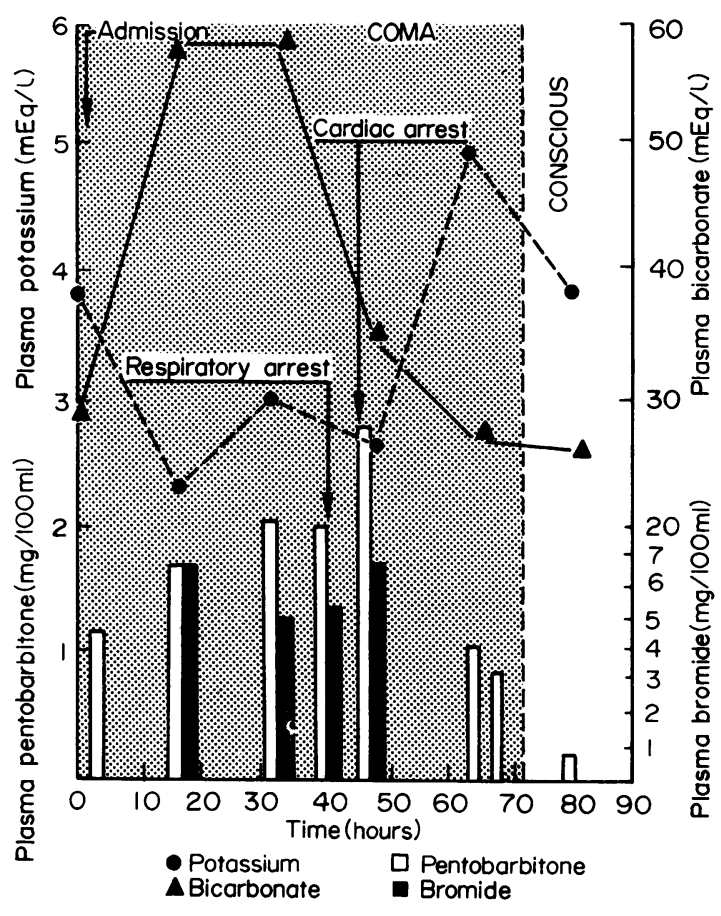

Fig. 3. Graph to show the relationship of serum concentrations of potassium and bicarbonate to serum concentrations of pentobarbitone and bromide.

Factors contributing to the cardiac arrest were even higher levels of both drugs, pentobarbitone
$2.75 \mathrm{mg} / 100 \mathrm{ml}$ plasma, and bromide $6.7 \mathrm{mg} / 100$ $\mathrm{ml}$ plasma; profound hypothermia, rectal temperature $89^{\circ} \mathrm{F}$; and hypokalaemia with a plasma potassium of $2.6 \mathrm{mEq} / \mathrm{l}$.

Mawer \& Lee (1968) have shown that renal excretion of unchanged pentobarbitone using forced alkaline diuresis has no therapeutic significance in the management of poisoning with pentobarbitone. Bloomer (1965) also found forced diuresis to have only limited value in the management of poisoning with this drug.

The results of this case suggest that their views apply equally to poisoning with Carbrital. The yield of pentobarbitione in the urine was insufficient to be helpful in management and dangerous complications may easily be produced by this technique.

It is suggested that the recommendations of Matthew \& Lawson (1966) for a policy of conservative management in the treatment of most cases of poisoning with intermediate-acting barbiturates should be followed in cases of poisoning with Carbrital.

\section{References}

MAwer, G.E. \& LeE, H.A. (1968) Value of forced diuresis in acute barbiturate poisoning. British Medical Journal, 2, 790-793.

BLOOMER, H.A. (1965) Limited usefulness of alkaline diuresis and peritoneal dialysis in pentobartital poisoning. New England Journal of Medicine, 272, 1309-1313.

MatThew, H. \& Lawson, A.A.H. (1966) Acute barbiturate poisoning. A review of two year experience. Quarterly Journal of Medicine, 35, 539-552.

\title{
Clostridium septicum infection of the thyroid gland
}

\author{
C. P. W. WARREN \\ M.B., B.CHIR., M.R.C.P. \\ Senior Medical Registrar
}
B. J. MASON
M.R.C.P.

Medical Registrar

\section{Royal Hampshire County Hospital, Winchester}

A CASE of infection of the thyroid gland by Clostri-
dium septicum is described, which is only the fourth
case of gas-forming suppurative thyroiditis to be
reported and the first in which the causative orga-
nism has been identified.

The case also illustrates a most unusual presentation of carcinoma of the colon.

\section{Case report}

A 58-year-old man who worked as a cold store attendant was admitted to hospital with a painful inflamed swelling of his neck. The swelling was in the region of the thyroid gland and had developed in $12 \mathrm{hr}$ with dysphagia and positional stridor. Rigors had occurred at the onset of the illness. His thyroid gland had been enlarged for 20 years and a firm enlargement of the right lobe had been noted on admission to hospital 2 years earlier. The patient looked ill and pale, and had a temperature of $103^{\circ} \mathrm{F}$. He was clinically euthyroid. His neck was swollen, inflamed and tender due to enlargement of the thyroid gland, particularly on the right side. There 
was neither crepitus nor fluctuation in the neck and the trachea could not be felt.

\section{Investigations}

$\mathrm{Hb} 6.5 \mathrm{~g} / 100 \mathrm{ml}$, RBC hypochromic and microcytic. WBC $23,000 / \mathrm{mm}^{3}, 94 \%$ neutrophils. ESR 18 $\mathrm{mm}$ in first $\mathrm{hr}$ (Wintrobe). Serum iron $25 \mu \mathrm{g} / 100 \mathrm{ml}$. Three blood cultures grew Clostridium septicum sensitive to penicillin. Urine-normal with no excess of urobilinogen. Serum haptoglobins normal. PBI $3.2 \mu \mathrm{g} / 100 \mathrm{ml}$. Latex test for thyroid antibodies negative.

$\mathrm{X}$-rays of the neck and chest showed that the thyroid gland was enlarged and contained gas (Figs. 1 and 2). The trachea was deviated to the left and the pharynx displaced forwards by the enlarged retropharyngeal space.

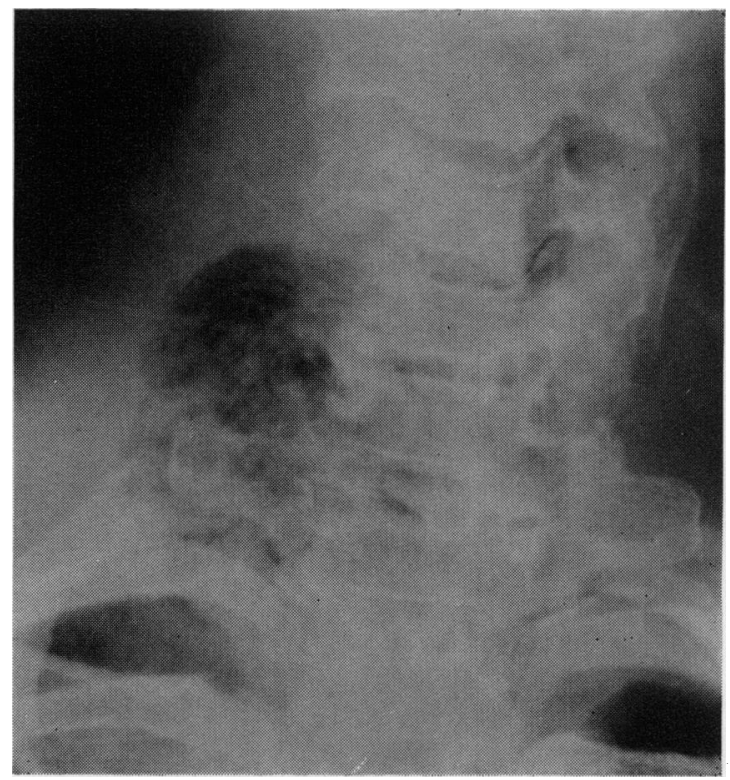

FIG. 1

\section{Progress}

A diagnosis was made of suppurative thyroiditis due to gas-forming bacteria, together with an iron deficiency anaemia. The patient was given a transfusion of 3 pints of blood and treatment was begun with benzylpenicillin and streptomycin-the latter being stopped when the blood culture results were obtained. The benzylpenicillin was continued in a dose of $2.4 \mathrm{~g}$ i.m. 6-hourly.

The patient improved during the first 2 days, the stridor disappeared and his temperature settled to $100^{\circ} \mathrm{F}$. On further questioning he admitted to a recent slight change in bowel habit. Occult blood

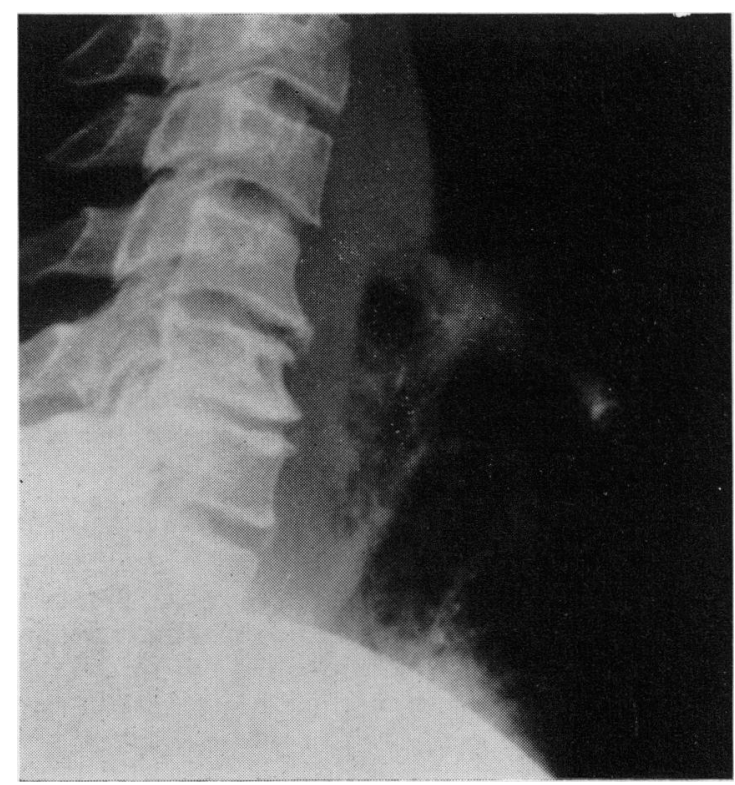

FIG. 2

was detected in his faeces, and a barium enema revealed radiological evidence of a carcinoma of the ascending colon.

During the next 10 days the patient felt well but a pyrexia of $99^{\circ} \mathrm{F}$ persisted and X-rays showed increased gas formation in the thyroid. Hyperbaric oxygen therapy was attempted but was discontinued because of the patient's claustrophobia. This treatment was delayed because it was feared that the pressure changes involved might lead to expansion of the gas in the thyroid gland and so increase the tracheal obstruction.

During the third week the swelling began to subside, the radiological abnormalities regressed and the patient became apyrexial. A right hemicolectomy was performed and the resected bowel was found to contain a large malignant ulcer extending through the bowel wall with no lymph node involvement. The histology was that of a moderately differentiated adenocarcinoma. Post-operative recovery was uneventful.

\section{Discussion}

We suggest that Clostridium septicum entered the blood stream through the carcinoma of the colon and settled in an anoxic area of the thyroid.

Bacterial infection of the thyroid is rare and infection of the gland by gas-forming organisms has been described on only three occasions. Joffe \& Schamroth (1966) described such a case and mention two others. Their patient was an African woman and her history and X-rays were similar to 
those described here. The authors were unable to isolate the organism and found no origin for the infection. No bacteria were isolated from the other two cases.

A pre-existing abnormality of the thyroid was present in our case and an adenoma was present in that of Joffe \& Schamroth. Abnormalities of the gland were noted in five out of ten cases of suppurative thyroiditis recorded by Altemerer (1950).

Clostridium septicum is found chiefly in the soil but is also commonly present in the human bowel. It is one of the organisms involved in gas gangrene, but it may often contaminate wounds without any apparent pathological consequence and will only flourish when the oxygen tension is low.

The anaemia in this case was due to iron deficiency and not to haemolysis. Clostridium septicum produces haemolytic toxins: Rathburn (1968) has reported twenty-two cases of clostridial bacteraemia without haemolysis although he did not record the haemoglobin or tests to exclude haemolysis in any case described.

In the treatment of clostridial infection the most important measure is full surgical excision of the infected area (Willis, 1964). This was unnecessary in this case because of the short history and the satisfactory response to antibiotics. Joffe \& Schamroth drained the thyroid region in their patient to remove necrotic tissue and pus. Antibiotics should be given, usually penicillin in large doses (Pyrtek $\&$ Bartus, 1962) and the patient may be placed in a hyperbaric oxygen chamber to increase the tissue oxygen tension and so impede the growth of the organisms (Brummelkamp, Boerema \& Hoogendyke, 1963). Antigasgangrene serum was not used in this patient and the efficacy of this treatment is uncertain (Oakley, 1954).

One interesting aspect of this case is the entry of the Clostridium into the blood stream. The organism is normally present in the bowel and presumably it entered through the carcinomatous ulcer. Clostridial infections have been reported following trauma (Willis, 1964), bowel surgery (McDonald, 1964), uterine infection (Hanson et al., 1966), cholecystitis (Yudis \& Zucker, 1967), and perianal abscesses
(Himal \& Duff, 1967). All these conditions are characterized by necrosis of tissue. Clostridia have been found in specimens removed from acute appendicitis but seem to play no part in its cause (Willis, 1964). It seems surprising that clostridial infection is not a more frequent complication of carcinoma of the colon or diverticulitis. Five of the cases reported by Rathburn had malignant disease. All but one of these patients suffered from a terminal disease or had been treated with cytotoxic drugs. The exception was a diabetic woman who developed a perforation of a carcinoma of the colon with acute peritonitis. Blood and peritoneal cultures grew Clostridium butyricum. She made a good recovery after surgery.

\section{Acknowledgments}

The patient was under the care of Dr D. A. F. McGill and we would like to thank him for his encouragement and his permission to report this case. We would also to thank Dr M. A. Hughes for his helpful criticism.

\section{References}

ALTMERER, W.A. (1950) Suppurative thyroiditis. Archives of Surgery, 61, 76.

BrummelKamp, W.H., Boerema, I. \& Hoogendyke, L. (1963) Treatment of clostridial infections with hyperbaric oxygen drenching. A report of 26 cases. Lancet, i, 25.

Hanson, G.C., Slack, W.K., Chew, H.E.R. \& Thomas, D.A. (1966) Clostridial infection of the uterus. Postgraduate Medical Journal, 42, 499.

HIMAL, H.S. \& DUFF, J.H. (1967) Endogenous gas gangrene. A report of 3 cases. Canadian Medical Association Journal, 97, 1541.

JoFFE, N. and Schamroth, L. (1966) Gas-forming infection of the thyroid gland. Clinical Radiology, 17, 95.

MCDonaLD, S. (1964) Clostridium welchii peritonitis after partial gastrectomy. Lancet, i, 308.

OAKLEY, C.L. (1954) Gas gangrene. British Medical Bulletin, $10,52$.

PyrTEK, L.J. \& Bartus, S.H. (1962) Clostridium welchii infection complicating biliary tract surgery. New England Journal of Medicine, 266, 689.

RATHBURN, H.K. (1968) Clostridial bacteraemia without haemolysis. Archives of Internal Medicine, 122, 496.

WILLIs, A.T. (1964) Anaerobic Bacteriology in Clinical Medicine (2nd Ed.) Butterworth, London.

YUDIS, M. \& ZUCKER, S. (1967) Clostridium welchii bacteraemia: A case report with survival and review of the literature Postgraduate Medical Journal, 43, 486. 